\title{
Uma Investigação sob a Percepção dos Usuários no Desempenho da Rede no IFC - Campus Avançado Sombrio
}

\author{
Diuliana de Matos da Rosa ${ }^{1}$, Liliana Campos Colares ${ }^{1}$, Matheus Lorenzato Braga ${ }^{1}$, \\ Victor Martins de Sousa ${ }^{1}$ \\ ${ }^{1}$ Instituto Federal Catarinense - Campus Avançado Sombrio (IFC-CAS) \\ Sombrio - SC - Brasil \\ \{diulymatos, colares.liliana\}@gmail.com, \\ \{matheus.braga, victor.sousa\}@ifc.edu.br
}

\begin{abstract}
This paper aims to assess the computer network performance of an educational institution by the view of their users. For doing that, an analysis took place through a initial questionnaire comparing a wired network to a wireless network. Based on the results, even wireless internet being slower, respondents consider the internet in the institution satisfactory.

Resumo. Este trabalho busca realizar um levantamento e análise, a partir da percepção dos usuários de uma instituição de ensino, em relação ao desempenho da rede ao passo que estes são os mais utilizadores do acesso à Internet. A análise se deu através de um questionário preliminar comparando uma rede cabeada com uma rede sem fio. Com base nos resultados, foi analisado que mesmo a Internet sem fio apresentando maior lentidão, os entrevistados consideram a Internet na instituição satisfatória.
\end{abstract}

\section{Introdução}

Conforme Olifer e Olifer (2014), foi possível observar o crescente aumento da Internet. Deste modo, as redes de computadores ficaram cada vez mais complexas, exigindo um bom gerenciamento. O gerenciamento da rede, nada mais é do que ter o controle e poder agir em função de informações coletadas que demonstrem anormalidade de funcionamento (SANTOS et al., 2015).

No Instituto Federal Catariense - Campus Avançado Sombrio (IFC-CAS) existem cursos nível de médio/técnico e ensino superior. Além do acesso à Internet disponível para todos os alunos, possui computadores nos laboratórios de informática, nos setores administrativos e na biblioteca.

O presente trabalho busca analisar a percepção dos usuários em relação ao desempenho da rede do IFC-CAS, a fim de apresentar o resultado aos administradores da rede, fazendo com que exista uma comparação entre a percepção dos usuários e os dados das ferramentas de monitoramento. Para isso, como forma de avaliação um questionário foi aplicado com os alunos e servidores da instituição para análise.

\section{Procedimentos Metodológicos}

Para o desenvolvimento foi utilizado um questionário aplicado com os usuários da rede, com um total de 147 respostas, sendo 138 discentes e 9 docentes. O grau de satisfação dos usuários da rede do IFC-CAS é um importante indicador e para avaliar a percepção dos usuários foi aplicado um questionário através da ferramenta Google Forms.

Este foi acessado através dos computadores nos laboratórios de informática no 
período de aula e os questionamentos foram desenvolvidos para que as respostas dos usuários fossem analisadas para mais tarde comparar então com as ferramentas utilizadas pela instituição. Para a obtenção de resultados iniciais desta pesquisa, as seguintes perguntas foram realizadas: a) "Você percebe diferença em relação a velocidade da rede cabeada e a rede WiFi?"; b) "Você percebe que a rede WiFi apresenta lentidões durante o uso?”; c) “A velocidade da Internet é satisfatória”.

Neste trabalho não estão presentes todas as perguntas aplicadas aos usuários, visto que se trata de um levantamento preliminar. Por se tratar de poucos usuários envolvidos, novos dados podem surgir com a ampliação do público-alvo.

\section{Resultados Parciais}

O questionário foi uma forma de analisar a percepção dos usuários sobre o desempenho da rede do IFC-CAS. Em relação a velocidade da rede cabeada e $\mathrm{WiFi}$, 81,6\% responderam "Sim”, 11,6\% "Não" e 6,8\% "Não se aplica”. Outra questão abordada foi sobre lentidões na rede durante o uso. Os resultados foram 77,6\% "Sim" e 22,4\% "Não". Além disso, foi realizada também uma pergunta para saber se a velocidade da Internet é satisfatória, sendo que os resultados foram 8,8\% "Concordo Plenamente", 56,5\% "Concordo", 13,6\% "Indiferente”, 18,4\% “Discordo” e 2,7\% “Discordo Plenamente”.

Deste modo, de acordo com a análise das respostas pode-se concluir que há diferença entre a rede cabeada e a rede WiFi, sendo que a rede WiFi apresenta lentidões durante o uso, mas, ainda assim, os usuários concordam que a velocidade da Internet é satisfatória. Em vista disso, quantidade de usuários simultâneos, equipamentos de rede e/ou hierarquia da rede podem interferir neste desempenho. Entretanto, ainda não foram analisadas quais aplicações apresentam esta lentidão, nem horários específicos.

A partir destes dados qualitativos fornecem uma vertente para novos resultados a serem analisados, além da identificação de diferentes horários de mudança da velocidade, principais aplicativos acessados e configuração dos equipamentos de rede existentes.

\section{Considerações Finais}

Este trabalho teve o intuito de analisar a percepção dos usuários da rede do IFC- CAS, em relação ao uso e desempenho da rede de computadores. Como o trabalho apresenta resultados preliminares, pretende-se aplicar o questionário com todos os usuários da instituição. Assim, realizar uma avaliação dos gráficos das ferramentas utilizadas para o monitoramento de rede, testes de velocidade em diferentes endereços IPs, comparação entre a percepção dos usuários e dos dados das ferramentas de monitoramento da rede e fazer uma análise dos equipamentos de rede utilizados atualmente no IFC-CAS. Além disso, em relação aos problemas que podem vir a ser identificados, sugestões de melhorias serão realizadas para que assim eles sejam resolvidos.

\section{Referências}

Kurose, J F., Ross, K W. (2010). Redes de Computadores e a Internet: Uma abordagem top-down. ISBN.

Oliffer, N., Oliffer, V. (2014). Redes de Computadores: Princípios, Tecnologias e Protocolos para Projeto de Redes. Focus.

Santos, M T et al. (2015). Gerência de Redes de Computadores. Escola Superior de Redes.

Stato Filho, A. (2014). LINUX: Controle de Rede. Visual Books. 